\title{
Energy Dispersive X-Ray Fluorescence Determination of Gallium in Aqueous Uranium Solution and (U-Ga) Mixed Oxide Powders
}

\author{
V. Natarajan*, P.J. Purohit, Neelam Goyal, N.K. Porwal, and S.V. Godbole \\ Radiochemistry Division \\ Bhabha Atomic Research Centre \\ Trombay, Mumbai 400 085, India
}

\section{INTRODUCTION}

Gallium (Ga) compounds such as GaN and GaAs are used as semiconductors, especially in light-emitting diodes, while the new photovoltaic compound $\mathrm{Cu}(\mathrm{In}, \mathrm{Ga})(\mathrm{Se}, \mathrm{S})_{2}$ is reported to be useful in solar panels as an alternative to crystalline silicon (1). Since Ga readily alloys with most metals, it is used as a component in low-melting alloys. In particular, it helps to stabilize the allotropes of plutonium. Ga-U and Ga-Pu systems have been studied for the development of new metal fuel reactors with respect to their thermodynamic stability for high temperature applications (2). Gallium is known to degrade the properties of many metallic materials via corrosion, embrittlement, or intermetallic phase formation. Thus, sensitive and reliable methods for the determination of trace and minor concentrations of Ga are required in these types of materials.

For the determination of trace amounts of $\mathrm{Ga}$, analytical techniques such as atomic absorption spectrometry (3), neutron activation analysis (4), and atomic emission spectrometry (AES) (5) are being used. While neutron activation methods are applicable to sub- $\mu$ g levels, the detection limits for methods based on molecular absorption or fluorescence are higher $(6,7)$. Determinations using inductively coupled plasma optical emission spectrometry (ICP-OES) (6), inductively coupled plasma mass spectrometry (ICP-MS) (7),

\footnotetext{
* Corresponding autbor.

E-mail:vnatra@yaboo.co.in

Fax: +9122 25505151
}

\begin{abstract}
Energy dispersive X-ray fluorescence (EDXRF)-based methods were developed for the determination of gallium (Ga) in aqueous solution using a set of standard solutions in the concentration range of $20-5000 \mu \mathrm{g} / \mathrm{mL}$. When these methods were applied to the determination of $\mathrm{Ga}$ in U-containing solutions, the estimated values were found to be lower due to matrix effects. Hence, they were modified using another set of Ga standards containing $\mathrm{U}$ concentrations at 100 $\mathrm{mg} / \mathrm{mL}$. The modified method was found to be applicable for the estimation of Ga from 50 $\mu \mathrm{g} / \mathrm{mL}$ to $5 \mathrm{mg} / \mathrm{mL}$ (i.e., $0.005 \%$ to $0.5 \% \mathrm{Ga}$ in $\mathrm{U}$ ).

Synthetic samples were analyzed by these methods in order to evaluate their reliability and reproducibility. Another method was also developed for the direct determination of Ga in (U-Ga) mixed oxide powders in the concentration range of 0.02 to 50 $\mathrm{mg} / \mathrm{g}$. The developed methods will be especially useful for the fast routine determination of $\mathrm{Ga}$ in U-Ga alloys.
\end{abstract}

and fluorimetry $(8,9)$ involve separation of interfering ions. Electrochemical techniques are reported to be good and sensitive for the determination of $\mathrm{Ga}$ at the $10 \mu \mathrm{g} / \mathrm{mL}$ level (10). Laser-induced breakdown spectroscopy has also been used for the determination of $\mathrm{Ga}$ in liquid matrices (11). These techniques, though sensitive, are time-consuming and have disadvantages such as the need for dissolution, chemical pre-concentration, separation treatment of the samples, and other manipulations. Total X-ray reflection spectrometry (TXRF) is reported to be very sensitive for many trace elements with detection limits in the order of $0.1 \mathrm{ng} / \mathrm{mL}$. However, Ga is usually used as the internal standard in the TXRF technique.

Energy dispersive X-ray fluorescence (EDXRF) spectrometry is known to be a simple, fast, nondestructive technique with adequate sensitivity (10-50 $\mu \mathrm{g} / \mathrm{mL})$ for many elements (12). In particular, this technique is expected to be useful for the determination of $\mathrm{Ga}$ (1000-10,000 $\mu \mathrm{g} / \mathrm{g}$ ) in U/Pu alloys after sample dissolution.

In the present work, feasibility studies were carried out for the determination of $\mathrm{Ga}$ in aqueous uranium solutions. This was done by establishing an EDXRF method for the analysis of dissolved U-Ga alloy samples. In our laboratory, (U-Ga) alloy samples are normally converted into oxide form for the determination of common metallic impurities by carrier distillationbased DC arc-atomic emission spectrometry. For this reason, a method for the direct determination of $\mathrm{Ga}$ in a (U-Ga) oxide mixture in powder form was also developed. The effect of common impurities in the determination of $\mathrm{Ga}$ in a (U-Ga) oxide mixture was examined. Electrothermal atomic absorption spectrometric (ETAAS) measurements were done using a modular type Varian Techron AA-6 AAS equipped with a pyrolytically coated carbon rod atomizer (Varian Inc., USA), while ICP-OES measurements were done using a Jobin-Yvon axial ICPOES spectrometer (Yobin Yvon Inc., France). 


\section{EXPERIMENTAL}

\section{Instrumentation}

The EDXRF measurements were carried out with a Jordan Valley EX 3600-M spectrometer, equipped with an Rh anode $\mathrm{X}$-ray tube, an assembly of six filters, a Ge secondary target and $\mathrm{Si}(\mathrm{Li})$ detector (1-40 keV) in air (Jordan Valley Co., USA). The system software (nEXt) for spectra acquisition and analysis runs were performed using the Windows ${ }^{\circledR}$ NT 4.0 or higher operating system. The $\mathrm{Si}(\mathrm{Li})$ detector has a resolution of $139 \mathrm{eV}$ at $\mathrm{Mn}-\mathrm{K} \alpha(5.9 \mathrm{keV})$ and is capable of acquiring a spectrum in the $1-40 \mathrm{keV}$ energy region. The data acquired were processed with the help of an attached computer. The resulting intensity is expressed in counts per second (cps).

\section{Standard Solutions}

Two sets of synthetic Ga standard solutions in the concentration range of 20 to $5 \mathrm{mg} / \mathrm{mL}$ were prepared. The first set contained only Ga, while the second set contained varying concentrations of $\mathrm{Ga}$ (20 to $5 \mathrm{mg} / \mathrm{mL}$ ) and a fixed concentration of $\mathrm{U}(100 \mathrm{mg} / \mathrm{mL})$. About $8 \mathrm{~mL}$ each of the above solutions was transferred into special plastic cups (25 mm dia.) with a thin Mylar ${ }^{\circledR}$ film (thickness of $6.3 \mu$ ) at the bottom for EDXRF analysis.

Two synthetic samples were prepared and analyzed by the proposed EDXRF method and also by graphite furnace AAS (GFAAS). One synthetic aqueous standard each was analyzed by EDXRF, ETAAS, and ICP-OES for comparison purposes. One set of aqueous solutions with a fixed Ga concentration and varying amounts of $U$ (1-100 mg/mL) was prepared to examine the matrix effects, i.e., the interference from $\mathrm{U}$ on the determination of $\mathrm{Ga}$.

For the determination of $\mathrm{Ga}$ in (U-Ga) mixed oxides, the samples in the form of powder $(200 \mathrm{mg})$ were kept inside a Teflon ${ }^{\circledR}$ cup assembly, covered at the bottom with a thin Mylar film. A series of synthetic powder standards with Ga concentrations ranging from $0.02-5.0 \%$ were prepared by mixing and grinding stoichiometric amounts of high purity $\mathrm{U}_{3} \mathrm{O}_{8}$ and $\mathrm{Ga}_{2} \mathrm{O}_{3}$. Grinding was done for 30 minutes using pestle and mortar.

The optimum parameters for the determination of Ga were obtained by varying the X-ray tube current, voltage, and counting times and using the standard containing 5\% Ga. All measurements were performed in air. Three synthetic (U-Ga) oxide samples were prepared for counter-checking the method. In addition, three other (U-Ga) oxide samples containing 100, 500, and $1000 \mu \mathrm{g} / \mathrm{g}$, respectively, of some common impurities such as $\mathrm{Ca}, \mathrm{V}$, $\mathrm{Fe}, \mathrm{Cr}, \mathrm{Mn}, \mathrm{Cu}, \mathrm{Ni}, \mathrm{Co}, \mathrm{Zn}$ (along with $10 \mathrm{mg} / \mathrm{g}$ of $\mathrm{Ga}$ ) were also analyzed by the developed method.

\section{RESULTS AND DISCUSSION}

\section{Aqueous Solutions}

The standard with the highest concentration of $\mathrm{Ga}$ was used for optimizing the experimental parameters. The X-ray tube current and voltage was varied using different filters (method 1 with a $\mathrm{Cu}$ filter and method 2 with a Mo filter) to obtain maximum count rates with a high signal-to-back-ground ratio. Table I lists the results of both methods in which eight synthetic standard solutions were counted under identical conditions in triplicate. Using a linear calibration program, calibration plots were obtained using a Cu filter (background at the Ga Ko X-ray peak is reduced due to CuK X-ray absorption) as well as a Mo filter (background around Ga X-ray is less since it is far away from the MoK edge). The calibration plots obtained for $\mathrm{Ga}$ in aqueous solutions using methods 1 and 2 are shown in Figure 1. The precision of the determinations was better than $2 \%$, while the limit of

TABLE I

Optimum Parameters for Ga Determination in Aqueous Solution Using $\mathrm{K} \alpha \mathrm{X}$-Rays

\begin{tabular}{cccc}
\hline $\begin{array}{c}\text { Method. Filter } \\
\text { No. }\end{array}$ Used $\begin{array}{c}\text { Optimum } \\
\text { Param- } \\
\text { eters }\end{array}$ & $\begin{array}{c}\text { Conc. } \\
\text { Range } \\
(\mu \mathrm{g} / \mathrm{mL})\end{array}$ \\
\hline 1. Cu filter & $\begin{array}{c}25 \mathrm{kV}, \\
200 \mu \mathrm{A},\end{array}$ & $20-5000$ \\
& & $180 \mathrm{~s}$, air \\
& & $30 \mathrm{kV}, \quad 50-5000$ \\
2. Mo filter & $350 \mu \mathrm{A}$ \\
& & $180 \mathrm{~s}$, air \\
&
\end{tabular}

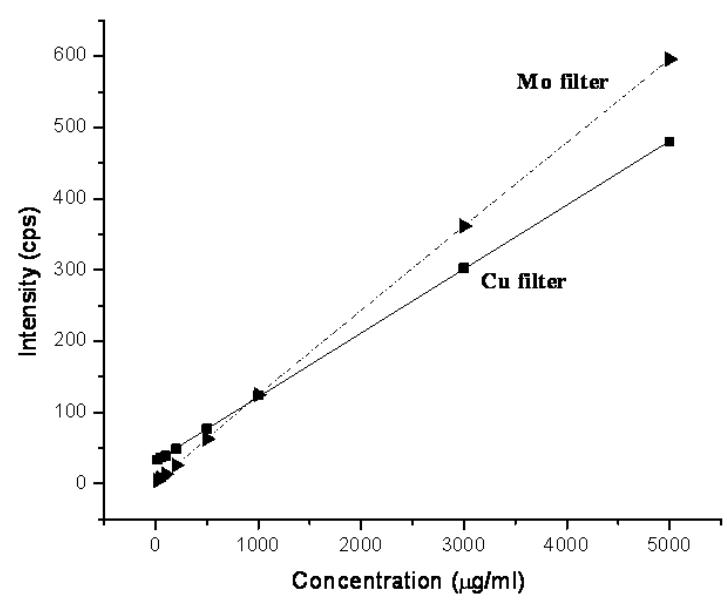

Fig. 1. Calibration plots for Ga determination in aqueous solutions. 
quantification using a $\mathrm{Cu}$ and Mo filter was 15 and $35 \mu \mathrm{g} / \mathrm{mL}$, respectively. For the Ga determination up to $1 \mathrm{mg} / \mathrm{mL}$, the Cu filter method is better than the Mo filter method. This is due to the reduced Compton background for $\mathrm{Ga}$ in the presence of the Cu filter (K edge: $9.0 \mathrm{eV}$ ).

The effect of varying the concentrations of $U$ on a fixed concentration of $\mathrm{Ga}(200 \mu \mathrm{g} / \mathrm{mL})$ was studied by monitoring the intensities of $\mathrm{Ga}$ K $\alpha$ X-rays using methods 1 and 2 . The results are listed in Table II. As shown in Figure 2, the decrease in Ga K $\alpha$ X-ray intensity with the concentration of $U$ is nearly exponential, indicating that the absorption of Ga X-rays by $U$ is the main rea- son. Reduction of the Ga signal intensity was found to be minimum for $\mathrm{U}$ concentrations at $1 \mathrm{mg} / \mathrm{mL}$ (6\%), while it was maximum for $\mathrm{U}$ concentrations at $100 \mathrm{mg} / \mathrm{mL}$ (65\%). Hence, separate optimizations of the X-ray tube parameters (Table III) and calibration plots (Figure 3) were established using a second set of standards containing $\mathrm{U}$ at a constant concentration of $100 \mathrm{mg} / \mathrm{mL}$ for the determination of Ga. It may be noted that a lower tube current and voltage was used when the Mo filter method was used for the determination of $\mathrm{Ga}$ in the presence of $U$ than for the determination of $\mathrm{Ga}$ in aqueous solutions. This was primarily done

TABLE II

Effect of U on the Intensity of Ga (conc. $-200 \mu \mathrm{g} / \mathrm{mL}$ ) $\mathrm{K} \alpha$ X-Rays

\begin{tabular}{|c|c|c|}
\hline $\begin{array}{l}\text { U conc. } \\
(\mu \mathrm{g} / \mathrm{mL})\end{array}$ & $\begin{array}{c}\text { I(cps)/Estimated Conc. } \\
(\mu \mathrm{g} / \mathrm{mL}) \\
(\mathrm{Cu} \text { Filter Method })\end{array}$ & $\begin{array}{c}\text { I(cps)/Estimated Conc } \\
(\mu \mathrm{g} / \mathrm{mL}) \\
\text { (Mo Filter Method) }\end{array}$ \\
\hline 0 & $53.4 / 221$ & $34.4 / 230$ \\
\hline 1 & $48.3 / 189$ & $25.9 / 194$ \\
\hline 5 & $48.0 / 183$ & $25.7 / 188$ \\
\hline 10 & 46.2 / 162 & $22.2 / 162$ \\
\hline 20 & 44.4 / 142 & $18.9 / 135$ \\
\hline 50 & $39.6 / 104$ & $14.2 / 107$ \\
\hline 100 & $37.4 / 65$ & $10.2 / 61$ \\
\hline
\end{tabular}

TABLE III

Methods for Ga Determination in U-Containing Solutions Using its $\mathrm{K} \alpha \mathbf{X}$-Rays

\begin{tabular}{ccc}
\hline $\begin{array}{c}\text { Sample Method } \\
\text { No. }\end{array}$ & $\begin{array}{c}\text { Optimum } \\
\text { Param- } \\
\text { eters }\end{array}$ & $\begin{array}{c}\text { Conc. } \\
\text { Range } \\
(\mu \mathrm{g} / \mathrm{mL})\end{array}$ \\
\hline 1. Cu Filter & $30 \mathrm{kV}, \quad 20-5000$ \\
& $200 \mu \mathrm{A}$, \\
& $180 \mathrm{~s}$, air \\
2. Mo Filter & $25 \mathrm{kV}, \quad 50-5000$ \\
& $250 \mu \mathrm{A}$ \\
& $180 \mathrm{~s}$, air \\
\hline
\end{tabular}

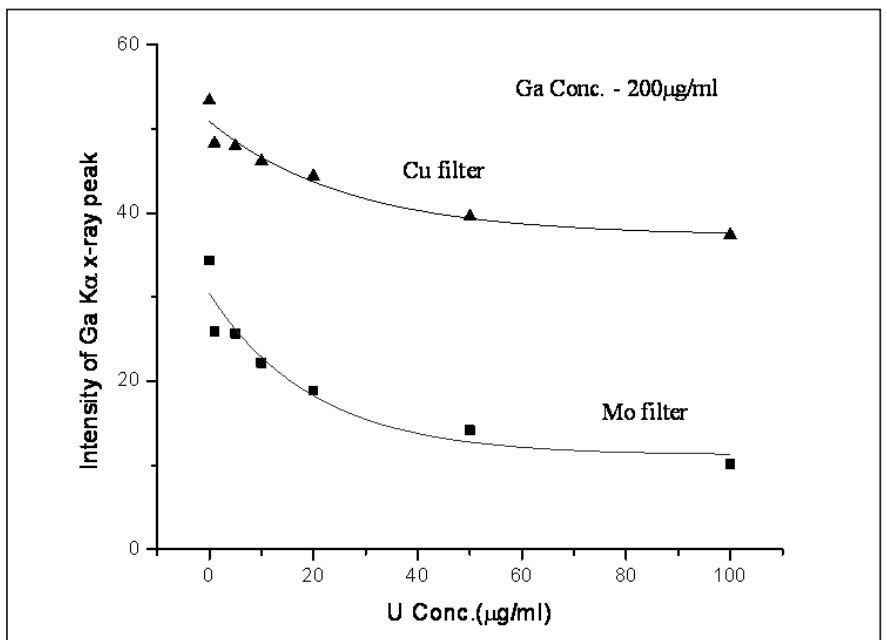

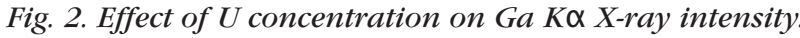

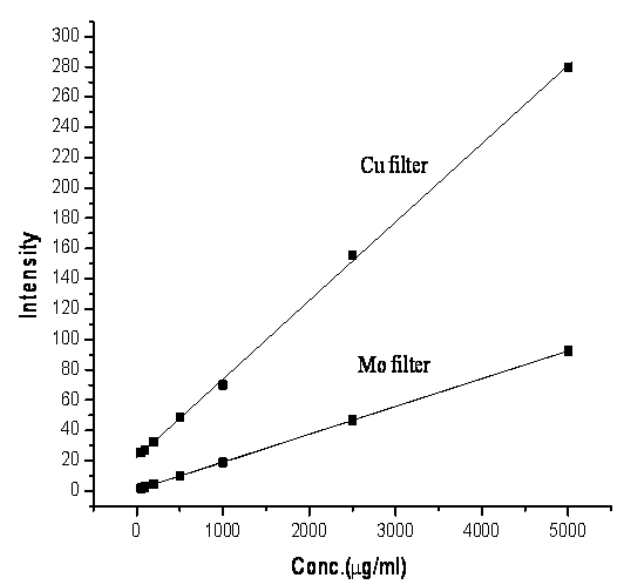

Fig.3. Calibration plots for Ga determination in $U$ (100 $\mathrm{mg} / \mathrm{mL}$ ) containing solutions. 
reasonably good (within $\pm 5 \%$ ). In general, the precision of the Ga determination by EDXRF was better than 3\% RSD down to $100 \mu \mathrm{g} / \mathrm{mL}$. Below $100 \mu \mathrm{g} / \mathrm{mL}$ of $\mathrm{Ga}$, the precision was between $\pm 5-10 \%$. One synthetic Ga standard (concentration of $100 \mu \mathrm{g} / \mathrm{mL}$ ) was analyzed in quadruplicate by EDXRF, ETAAS, and ICP-OES. The determined concentration values were $94 \pm 3 \mu \mathrm{g} / \mathrm{mL}$, $101 \pm 1 \mu \mathrm{g} / \mathrm{mL}$, and $108 \pm 2 \mu \mathrm{g} / \mathrm{mL}$, respectively. This also demonstrated the utility of the developed methods.

\section{(U-Ga) Oxide Powders}

The optimum parameters for the determination of $\mathrm{Ga}$ in (U-Ga) oxide powder were determined by counting the different standards with different filters, tube voltages, and currents, and are listed in Table V. It should be noted that the optimum parameters were changed for the determination of $\mathrm{Ga}$ at the $\mathrm{mg} / \mathrm{g}$ level.

The calibration plot of the Ga $\mathrm{K} \alpha \mathrm{X}$-ray intensity against its concentration was linear in the concentration range of $20-5000 \mu \mathrm{g} / \mathrm{g}$ (Figure 4), indicating the absence of significant matrix effects in this range. However, Figure 5 shows

TABLE IV

Analysis of Aqueous Ga Samples Using EDXRF and ETAAS

\begin{tabular}{|c|c|c|c|c|c|}
\hline \multicolumn{2}{|c|}{$\begin{array}{c}\text { Sample } 1 \\
\text { (Added Ga } 3000 \mu \mathrm{g} / \mathrm{mL}) \\
\text { Determined }(\mu \mathrm{g} / \mathrm{mL})\end{array}$} & \multicolumn{2}{|c|}{$\begin{array}{c}\text { Sample } 2 \\
\text { (Added Ga } 1000 \mu \mathrm{g} / \mathrm{mL}) \\
\text { Determined }(\mu \mathrm{g} / \mathrm{mL})\end{array}$} & \multicolumn{2}{|c|}{$\begin{array}{c}\text { Sample } 3 \\
\text { (Added Ga } 100 \mu \mathrm{g} / \mathrm{mL}) \\
\text { Determined }(\mu \mathrm{g} / \mathrm{mL})\end{array}$} \\
\hline EDXRF & ETAAS & EDXRF & ETAAS & EDXRF & ETAAS \\
\hline $3006 \pm 6^{a}$ & $3125 \pm 120^{c}$ & $1032 \pm 10^{\mathrm{a}}$ & $981 \pm 30^{c}$ & $103 \pm 2^{\mathrm{a}}$ & $101 \pm 5^{c}$ \\
\hline $3019 \pm 8^{b}$ & & $1020 \pm 6^{b}$ & & $99 \pm 2^{\mathrm{b}}$ & \\
\hline
\end{tabular}

${ }^{\mathrm{a}-} \mathrm{Cu}$ filter method.

${ }^{\mathrm{b}}$ Mo filter method.

${ }^{\mathrm{c}}$ ETAAS (samples were diluted by 100-1000 times and hence the precision was poorer).

Number of determinations $=4$.

\section{Atomic Mpectroscopy \\ 1 Vol. 34(2), March/April 2013}

that in the concentration range of $5 \mathrm{mg} / \mathrm{g}(0.5 \%)$ to $50 \mathrm{mg} / \mathrm{g}(5 \%)$, the plot was non-linear. The intensity of Ga X-rays increased more at higher Ga concentrations. This is attributed to the significant change (reduction) in effective $\mathrm{Z}$ of the matrix, resulting in reduced matrix absorption and enhanced intensity of the Ga X-rays.

Three synthetic (U-Ga) oxide samples were prepared and analyzed by the developed EDXRF method. The agreement between the added and determined values was good. The precision of the determinations varied between $0.5-5.0 \%$ (see Table VI).

TABLE V

Optimized Parameters for Ga Determination in (Ga-U) Oxide Powder Mixture

\begin{tabular}{|c|c|c|c|}
\hline $\begin{array}{l}\text { Sample } \\
\text { No. }\end{array}$ & Method & $\begin{array}{l}\text { Optimum } \\
\text { Param- } \\
\text { eters }\end{array}$ & $\begin{array}{l}\text { Conc. } \\
\text { Range }\end{array}$ \\
\hline 1. & Mo Filter & $\begin{array}{l}25 \mathrm{kV}, \\
250 \mu \mathrm{A}, \\
180 \mathrm{~s}, \text { air }\end{array}$ & $\begin{array}{c}20-5000 \\
\mu \mathrm{g} / \mathrm{g}\end{array}$ \\
\hline 2. & Mo Filter & $\begin{array}{l}25 \mathrm{kV}, \\
500 \mu \mathrm{A} \\
180 \mathrm{s.}, \text { air }\end{array}$ & $\begin{array}{r}1-50 \\
\mathrm{mg} / \mathrm{g}\end{array}$ \\
\hline
\end{tabular}

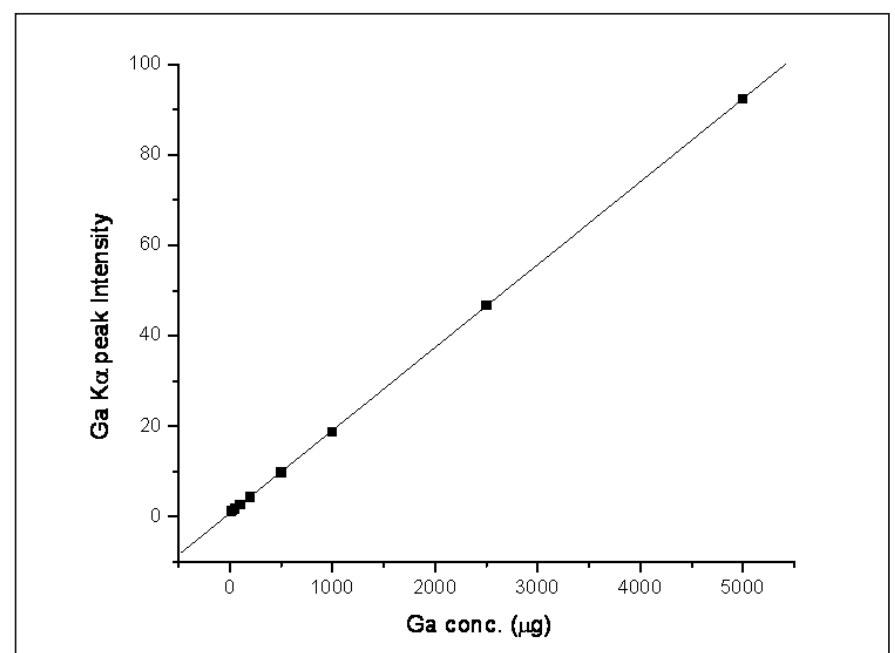

Fig. 4. Calibration for Ga in Ga-U oxide powder mixture $(20 \mu \mathrm{g} / \mathrm{g}-5 \mathrm{mg} / \mathrm{g})$.

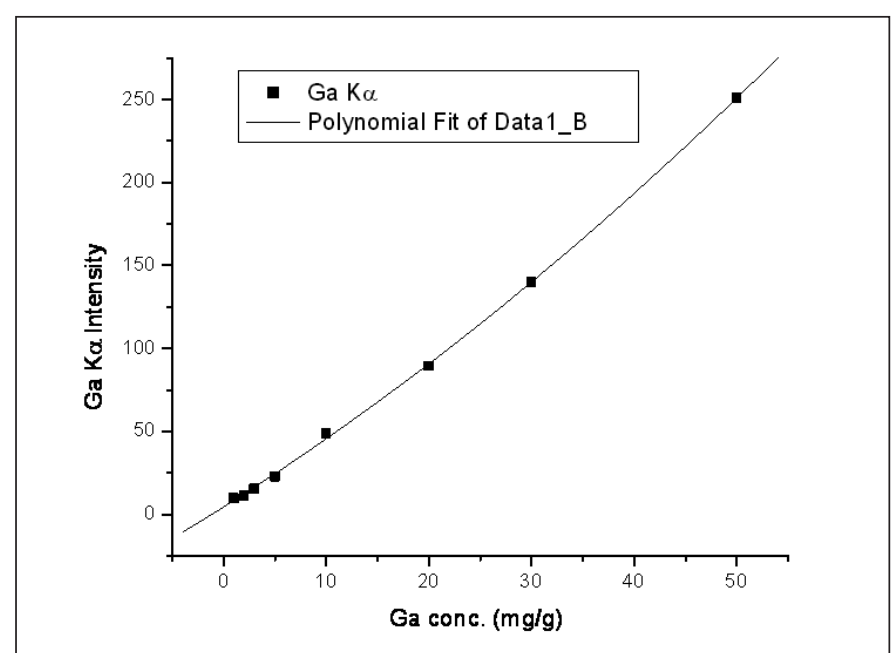

Fig. 5. Calibration for Ga in Ga-U oxide mixture (1-50 mg/g). 
In order to examine the effect of common impurities such as $\mathrm{Ca}$, $\mathrm{V}, \mathrm{Fe}, \mathrm{Cr}, \mathrm{Mn}, \mathrm{Cu}, \mathrm{Ni}, \mathrm{Co}$, and $\mathrm{Zn}$, three (Ga-U) oxide samples containing 100,500 , and $1000 \mu \mathrm{g} / \mathrm{g}$ of these common impurities (along with $10 \mathrm{mg} / \mathrm{g}$ of $\mathrm{Ga}$ ) were analyzed by the developed method. As can be seen in Table VII, the determined values were in good agreement with the added Ga concentration values, indicating tolerance of the method for common impurities.

\section{CONCLUSION}

Energy dispersive X-ray fluorescence (EDXRF) methods were developed for the fast and routine determination of $\mathrm{Ga}$ in aqueous/ U-containing solutions over a wide concentration range (50-5000 $\mu \mathrm{g} / \mathrm{mL}$ ) with reasonable precision and accuracy, without requiring chemical separation of the major matrix. Gallium can be determined in the presence of $U$ up to $1 \mathrm{mg} / \mathrm{mL}$ using aqueous standards. For higher concentrations of $U$, separate calibration standards or attenuation corrections are necessary.

In addition, an EDXRF method was developed for the direct determination of Ga in (U-Ga) mixed oxide powders over a wide concentration range with reasonable precision and accuracy. This method is fast, non-destructive, and does not involve any chemical separation or mixing with a binder. An internal standard could also be used to help with accurate quantification at higher uranium concentrations.

TABLE VI

Determination of Ga in Some Synthetic (U-Ga) Oxide Powder Samples in Quadruplicate

\begin{tabular}{|c|c|c|c|c|c|}
\hline \multicolumn{2}{|c|}{$\begin{array}{l}\text { Sample } 1 \\
\text { Added Determined } \\
\quad(\mathrm{mg} / \mathrm{g})\end{array}$} & \multicolumn{2}{|c|}{$\begin{array}{l}\text { Sample } 3 \\
\text { Added Determined } \\
\quad(\mathrm{mg} / \mathrm{g})\end{array}$} & \multicolumn{2}{|c|}{$\begin{array}{l}\text { Sample } 3 \\
\text { Added Determined } \\
\quad(\mathrm{mg} / \mathrm{g})\end{array}$} \\
\hline 0.1 & 0.107 & 5 & 4.66 & 10 & 10.07 \\
\hline 0.1 & 0.098 & 5 & 4.70 & 10 & 10.20 \\
\hline 0.1 & 0.103 & 5 & 4.77 & 10 & 9.98 \\
\hline 0.1 & 0.099 & 5 & 4.72 & 10 & 10.02 \\
\hline \multicolumn{6}{|c|}{$\begin{array}{l}\text { TABLE VII } \\
\text { Determination of Ga (10 } \mathrm{mg} / \mathrm{g}) \text { in Presence } \\
\text { of Some Common Impurities in Triplicate }\end{array}$} \\
\hline $\begin{array}{l}\text { Impurity } \\
\text { Conc. } \\
(\mu \mathrm{g} / \mathrm{g}) \\
\end{array}$ & $\begin{array}{l}\text { Determined } \\
\text { Ga Conc. } \\
(\mathrm{mg} / \mathrm{g})\end{array}$ & $\begin{array}{l}\text { Impurity } \\
\text { Conc. } \\
(\mu \mathrm{g} / \mathrm{g})\end{array}$ & $\begin{array}{l}\text { Determined } \\
\text { Ga Conc. } \\
(\mathrm{mg} / \mathrm{g})\end{array}$ & $\begin{array}{l}\text { Impurity } \\
\text { Conc. } \\
(\mu \mathrm{g} / \mathrm{g})\end{array}$ & $\begin{array}{l}\text { Determined } \\
\text { Ga Conc. } \\
(\mathrm{mg} / \mathrm{g})\end{array}$ \\
\hline 100 & 10.06 & 500 & 10.45 & 1000 & 10.84 \\
\hline 100 & 10.28 & 500 & 10.64 & 1000 & 10.92 \\
\hline 100 & 9.97 & 500 & 10.41 & 1000 & 11.05 \\
\hline
\end{tabular}

\section{REFERENCES}

1. M.D. Prat, R. Compano, M. Granados, and E. Miralles, J. Chromatogr. A 746, 239 (1996).

2. J. Wang, X.J. Liu and C.P. Wang, J. Nucl. Mater. 380, 105 (2008).

3. Y. Hayashibe, M. Kurosaki, F. Takekawa, and R. Kuroda, Mikrochim. Acta 98, 163 (1989).

4. E.L. Lakomaa, P. Manninen, R.J. Rosenberg, and R. Zilliacus, J. Radioanal. Nucl. Chem. 168, 357 (1993).

5. W. Slavin, Anal. Chem. 58, 589A (1986).

6. Mithlesh Kumar, M. Mohapatra, P.J. Purohit, S.K. Thulasidas, T.K. Sehagiri, Neelam Goyal and S.V. Godbole, At. Spectrosc. 31, 97 (2010).

7. J.C. Yu and C.M. Wai, Anal. Chem. 56, 1689 (1984).

8. D. Kara, A. Fisher, M. Foulkes and S.J. Hills, Spectrochim. Acta A75, 361 (2010).

9. K.J. Orians and E.A. Boyle, Anal. Chim. Acta 282, 63 (1993)
10. T.K .Bharadwaj, H.S. Sharma and S.K. Aggarwal, J. Nucl. Mater. 360, 215 (2007).

11. A. Sarkar, D. Almelu and S.K. Aggarwal, Optics 7 Laser Techn. 44, 30 (2011).

12.V. Natarajan, N.K. Porwal, Y. Babu, B. Rajeswari, B.A. Dhawale, Mithlesh Kumar, S.V. Godbole, and V.K. Manchanda, Appl. Radiat. Isot. 68, 1128 (2010). 


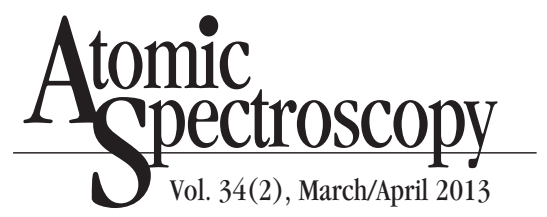

\section{AUTHOR CORRECTIONS FOR VOLUME 34, NO. 1, JANUARY/FEBRUARY 2013 ISSUE}

Please note author corrections for Volume 34, No 1, January/February 2013 issue, in article entitled:

Determination of $U, S, V, C u, Z n, S r, M o$, and Ce in Carbonate Rocks by Wavelength Dispersive X-Ray Fluorescence Spectrometry and ICP-OES by Chancal Sarbajna et al.

pg. 31, Abstract section, middle column:

line 6 , reads "Mo $(10.1 \%$, at $10 \mathrm{ppm})$ "

- but should read: Mo (10.0\% at $10 \mathrm{ppm})$

line 10 , reads "Ce $(5.2 \%$, at $10 \mathrm{ppm})$ "

- but should read: $\mathrm{U}(5.2 \%$, at $10 \mathrm{ppm})$

pg. 35, Table III, 4th column, titled DL:

1 st line, 4th column, reads " 0.017 "

- but should read: 0.17

2nd line, 4th column, reads "0.095"

-- but should read: 0.95 